\title{
Parametric Analysis of Horizontal Acceleration Response of Rock Slope to Seismic Waves in a Shaking Table Test
}

\author{
Hanxiang Liu*, Qiang Xu, Xing Zhu \\ State Key Laboratory of Geohazard Prevention and Geoenvironment Protection, Chengdu University of Technology, 1 Third \\ Road East, Erxianqiao, Chengdu, Sichuan, China 610059
}

\begin{abstract}
Studies on landslides triggered by the 2008 Wenchuan earthquake show that topography, geology and seismic source are of great importance in amplifying seismic waves and in determining spatial concentration of slope failures. A shaking table test on two rock slopes was carried out in the present study. The recorded Wenchuan earthquake waves were scaled to excite the model slopes. Based on the measurements from accelerometers installed on free surface of the model slopes, horizontal acceleration responses were analyzed. It is found that the amplification factor of peak horizontal acceleration, $R_{P H A}$, increases with elevation of each model slope, though the upper and lower halves of the slope exhibit different increasing patterns. Comparing the responses considering different lithology, excitation direction, intensity and frequency, the results show that: (1) the model slope with materials of low strength (HS model) produces horizontal responses over 2.5 times stronger than the model slope with materials of high strength (HH model) at the crest; (2) both PHA (Peak Horizontal Acceleration) and $R_{P H A}$ show general increase with the excitation intensity, indicating that the horizontal acceleration response of slopes gets strengthened before the slope deformation enters nonlinear phase; (3) the HS model presents frequency-dependent amplification at lower frequency than the HH model; and (4) the coupling effect of horizontal and vertical (XZ) direction shakings not only produces larger PHA amplification than the horizontal (X) direction shakings, but also a larger spectral amplification at high frequencies. The coupling effect indicates the non-ignorable role of vertical motions in response of a slope to an earthquake and should be considered in engineering design.
\end{abstract}

Keywords: seismic response, shaking table test, horizontal acceleration, topography, lithology, excitation parameters

\section{Introduction}

Tens of thousands of landslides were triggered by the 2008 Wenchuan earthquake in southwestern China (Yin et al 2009). Spatial distribution characteristics of the landslides demonstrate a close relation with topography, geologic conditions and seismic parameters (Qi et al 2010, Dai et al 2010, Gorum et al 2011). Most of the landslides occurred at elevations lower than $2000 \mathrm{~m}$ where valleys and ridges were well developed. Landslide density (landslides $/ \mathrm{km}^{2}$ ) reached its maximum in slope gradients of $30^{\circ}-40^{\circ}$, and in slopes composed of hard rocks (e.g. limestone, dolomite and granite). The density increased as the distance of study area from the epicenter or from the surface rupture decreased. The near-source ground motion observations (within $200 \mathrm{~km}$ ) partly explained that the increase of landslides in areas close to rupture fault was due to strong peak ground acceleration (PGA) (Wen et al 2010). However, few instrumental data are available for revealing the topographic and geological effects of slopes exposed to seismic waves. It is worth mentioning that, after the Wenchuan earthquake, a large number of accelerometer monitoring works have been carried out in the Weigan hill, Mount Dong and Mount Shizi in Qingchuan
County where many aftershocks occurred (Luo et al 2014). The results presented the topographic and geological effects in a quantitative way. Furthermore, directional amplification was observed based on the polar diagrams of normalized Arias intensity (defined by Arias (1970), representing the shaking energy for each recorded event over the entire duration) and the horizontal to vertical spectral ratios based on Fourier amplitude spectrums of accelerograms.

Modification of seismic waves caused by variation of surface topography has been recognized for years. Frequency-dependent amplification was observed at the crest of a ridge and a valley (Bouchon 1973, Rogers et al 1974, Wong 1982). A systematic review on topographic effects was made by Geli et al (1988), who compared theoretical and experimental results, and found qualitative agreement about the amplification at mountain tops. However, the time-domain crest/base amplification ratios remained below 2 in theoretical results, while the corresponding values reached around 8 in experimental results. Moreover, the theoretical crest/base spectral amplification ranges between 2 and 7 for other complex models, while the experimental spectral amplification can reach 30. Ashford and Sitar (1997) and Ashford et al (1997)

\footnotetext{
* Corresponding Author: Hanxiang Liu, Email: hxliu_86@163.com, Tel: +86 134-028-14301
} 
studied the homogeneous step-like slopes, and also observed the peak amplification at the crest. More importantly, they separated the crest amplification caused by the topography from that induced by natural frequency of region behind the crest. For the step-like slope, Bouckovalas and Papadimitriou (2005) further pointed out an amplification of 1.2-1.5 in horizontal and 0.1-1.1 in vertical as compared to free field response for vertical SV waves excitation.

Numerical modeling and field monitoring provide an important insight to the complex slope responses under coupling effect of multiple parameters. Assimaki et al (2005) performed two-dimensional elastic wave propagation analyses, and emphasized the role of soil stratigraphy and material heterogeneity on the spatial distribution, amplification level and frequency content of slope responses. In terms of field monitoring, using the aftershock data from a temporary dense array, Celebi $(1987,1991)$ reported an amplified spectral ratio, close to 40 , at ridges compared to rock stations. A higher amplification ratio of 100 occurred when combining the topographic and geological effects. Directional differences in shaking energy by a factor of 2-3 were obtained by Del Gaudio and Wasowski (2007), based on their long-term field monitoring in a potential landslide in

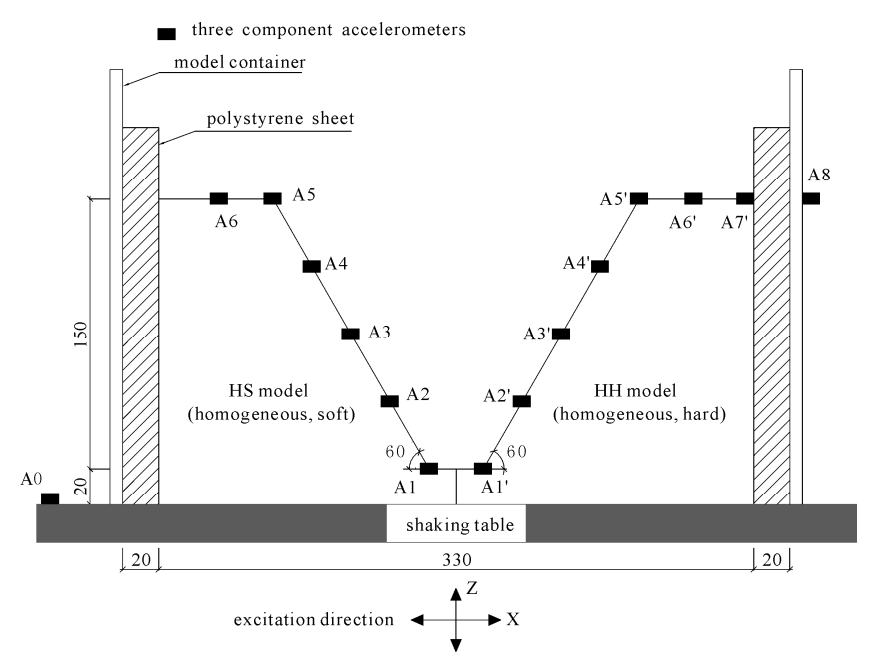

Figure 1. Set-up of the shaking table model

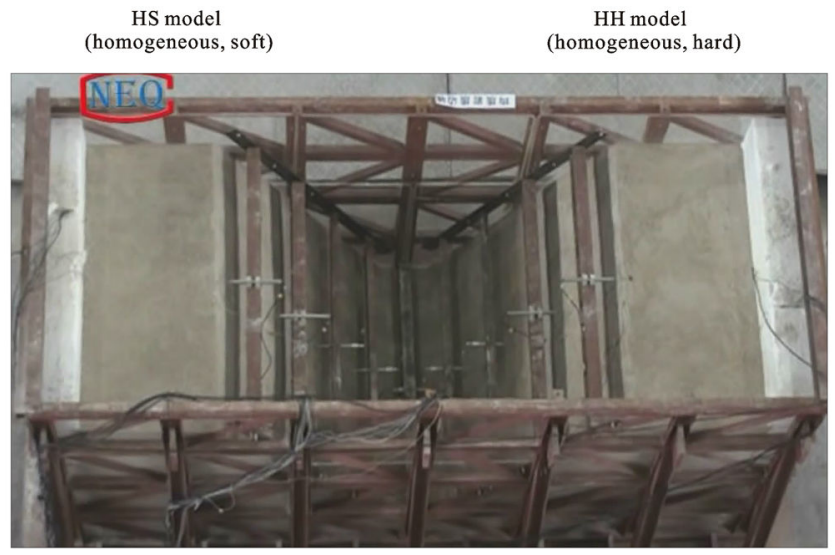

Figure 2. Overhead view of the model slopes
Italy. Differing from the instrumental data, results from numerical modeling and other analytical analysis are mostly limited in linear elastic region, without considering nonlinear seismic responses.

Shaking table model tests have been widely adopted in studies on slope response to seismic waves (Yang et al 2002, Ling et al 2005, Lin and Wang 2006, Wang and Lin 2011). Shimizu et al (1986) conducted three kinds of twodimensional model tests to investigate the dynamic failure modes of rock slopes. The maximum amplification of about $300 \%$ was observed in accelerometers embedded at the top of a shaking table model of $600 \mathrm{~mm}$ long and $400 \mathrm{~mm}$ high. Nowadays, studies in this particular field are carried out by using advanced shaking tables, which allow large models and diverse waves to be investigated (Liang et al 2005, Dong et al 2011, Ye et al 2013).

In the present study, a shaking table with six degrees of freedom (three translational motions and three rotational motions) is used to excite two model slopes composed of different lithology, soft rock and hard rock. Each model slope is instrumented by five three-component accelerometers at different elevations on the free surface. Waves with a broad range of shaking levels scaled from the 2008 Wenchuan earthquake recordings are used to excite the models in horizontal, vertical and their resultant directions. Only horizontal component responses of the two models to seismic waves are discussed in time domain, focusing on parameter analysis of topography, lithology, excitation direction and intensity. Responses are also explored in frequency domain for model slopes subjected to different levels of excitation intensities.

\section{Test Program}

\subsection{Model materials}

As shown in Figs. 1 and 2, two model slopes were prepared in the model container with homogeneous materials. The left model slope is composed of materials of low strength. This is used to simulate slopes with soft rocks, and is conveniently represented by HS model (Homogeneous, Soft). The lithologic properties refer to the bedrock, siliceous slate, overlaid by the Zhengjiashan landslide, which was triggered by the 2008 Wenchuan earthquake in Pingwu County (Xu et al 2009). The right model slope was composed of materials of high strength and is used to simulate slopes with hard rocks. It is conveniently represented by $\mathrm{HH}$ model (Homogeneous, Hard). The lithologic properties refer to bedrock, granite, overlaid by the Niumiangou landslide, which was also triggered by the 2008 Wenchuan earthquake (Xu et al 2009). The only variable of each model is slope height, and the only difference between the two models is lithology, without considering the slope structure. This simplification is useful for an understanding of the parameters necessary to quantify slope responses to seismic waves.

The Buckingham's $\pi$ theorem is based on dimensional analysis and gives the transformation from a function of dimensional parameters $\left(f\left(q_{1}, q_{2}, q_{3}, \ldots, q_{n}\right)=0\right)$ to a related function of dimensionless parameters $\left(F\left(\pi_{1}, \pi_{2}, \pi_{3}, \ldots, \pi_{4}\right)=\right.$ 
0) (Louis 1957, Curtis et al 1982). In the present study, soil density $\rho$, elastic modulus $E$ and time $t$ are selected as the controlling parameters, and their scale factors are 1.0, 32.6 and 4 , respectively. The scale factor of length $C_{\mathrm{L}}=22.6$ indicates the height of the prototype slope is $33.9 \mathrm{~m}$. Based on the controlling quantities, the $\pi$ terms for the $F$ function and the corresponding scale factors of the other key parameters, which represent the geometric, kinematic and dynamic features, are calculated, as shown in Table 1.

Barite powder, quartz sands, gypsum, glycerol and water were mixed in a weight ratio of $32: 54: 7.5: 1.5: 5.5$ to produce the high strength material of model slopes which simulates hard rock. A mixture of the same components in a ratio of $32: 56: 6: 1: 7$ was used to make the low strength materials, which simulates the soft rock. Note that the above ratios were determined through try and error. The barite powder (maximum particle size $0.074 \mathrm{~mm}$ ) and quartz sands ( 0.074 to $0.85 \mathrm{~mm}$ ) work as fine and coarse aggregates in the mixture, respectively. The gypsum and water work together as cement. Glycerol was used to slow down the curling of the mixture to achieve the desired strength. In accordance with Chinese Standard for Soil Test Method (GB/T 50123-1999), direct shear tests were conducted to obtain the cohesions, internal friction angles of the mixture and the mechanical properties of the interfaces between layers. Uniaxial compression strength tests were conducted to obtain the elasticity modulus. The properties of materials for model slopes and the prototype are listed in Table 2.

Table 1 . The $\pi$ terms and scale factors of key parameters

\begin{tabular}{lll}
\hline Quantities & Dimensionless $\boldsymbol{\pi}$ terms & Scale factor \\
\hline Density & Controlling parameter & $C_{\rho}=1$ \\
\hline Elasticity modulus & Controlling parameter & $C_{E}=32.6$ \\
\hline Time & Controlling parameter & $C_{t}=4$ \\
\hline Length & $\pi_{L}=L /\left(E^{0.5} \rho^{-0.5} t\right)$ & $C_{L}=C_{E}{ }^{0.5} C_{\rho}^{-0.5} C_{t}=22.9$ \\
\hline Poisson's ratio & 1 & $C_{\mu}=1$ \\
\hline Cohesion & $\pi_{\mathrm{c}}=c /(E)$ & $C_{c}=C_{E}=32.6$ \\
\hline Frictional angle & 1 & $C_{\Phi}=1$ \\
\hline Stress & $\pi_{\sigma}=\sigma /(E \varepsilon)$ & $C_{\sigma}=C_{E} C_{\varepsilon}=22.8$ \\
\hline Strain & $\pi_{\varepsilon}=\varepsilon /(\rho L / E)$ & $C_{\varepsilon}=C_{\rho} C_{L} / C_{E}=0.7$ \\
\hline Frequency & $\pi_{f}=f / t$ & $C_{f}=C_{t}^{-1}=0.25$ \\
\hline Displacement & $\pi_{\mathrm{u}}=u /(L \varepsilon)$ & $C_{u}=C_{L} C_{\varepsilon}=16$ \\
\hline Velocity & $\pi_{v}=v /\left(u t^{-1}\right)$ & $C_{v}=C_{u} C_{t}^{-1}=4$ \\
\hline Acceleration & $\pi_{a}=a /\left(u t^{-2}\right)$ & $C_{a}=C_{u} C_{t}^{-2}=1$ \\
\hline
\end{tabular}

Table 2. Physical and mechanical parameters of the prototype slopes and the model slopes

\begin{tabular}{|c|c|c|c|c|c|c|}
\hline \multicolumn{2}{|c|}{ Lithology } & $\begin{array}{c}\text { Density } \\
\rho\left(10^{3} \mathrm{~kg} / \mathrm{m}^{3}\right) \\
\end{array}$ & $\begin{array}{c}\text { Elasticity modulus } \\
E(\mathrm{MPa}) \\
\end{array}$ & $\begin{array}{c}\text { Poisson's Ratio } \\
\mu\end{array}$ & $\begin{array}{c}\text { Cohesion } \\
c(\mathbf{k P a})\end{array}$ & $\begin{array}{c}\text { Frictional } \\
\text { Angle } \Phi\left(^{\circ}\right)\end{array}$ \\
\hline \multirow{2}{*}{ Hard rock } & Prototype & 2.7 & 8940 & 0.23 & 1600 & 39 \\
\hline & Model & 2.52 & 253.2 & 0.26 & 83.4 & 36.5 \\
\hline \multirow{2}{*}{ Soft rock } & Prototype & 2.48 & 1900 & 0.31 & 520 & 33.8 \\
\hline & Model & 2.4 & 50.2 & 0.3 & 37.1 & 34.9 \\
\hline Interface & & & & & 18 & 19.2 \\
\hline
\end{tabular}

\subsection{Model preparation}

Two model slopes were prepared in a steel model container of $3.7 \mathrm{~m}$ long, $1.5 \mathrm{~m}$ wide, and $2.1 \mathrm{~m}$ high (Figs. 1 and 2 ). The height of each model slope is $1.5 \mathrm{~m}$. To minimize the influences of the boundary of model container on the input seismic waves, an absorber made of polystyrene sheet wrapped with polyethylene film was placed on the two sides of each container, perpendicular to X-direction (Fig. 1). A $20 \mathrm{~cm}$ thick foundation, with the same material to the model slope, was laid at the bottom of the model container. Each model slope was prepared by wet pouring and compacting, layer by layer, a certain volume of mixed material into a 15 $\mathrm{cm}$ thick layer. Such a method ensures the desired unit weights as listed in Table 2. During building-up the model slopes, a modeler was used to keep the slope angle at the designated $60^{\circ}$. The final products are two model slopes standing face to face in a model container, forming a Ushaped valley as shown in Fig. 2.

\subsection{Test set-up}

The shaking table used in this study has a capacity of $60 \mathrm{t}$, and the maximum working frequency is $80 \mathrm{~Hz}$. The size of the table is $6.0 \mathrm{~m}$ by $6.0 \mathrm{~m}$, and allows the placement of two model containers in this test. The ranges of displacement are -150 to $+150 \mathrm{~mm}$ in two orthogonally horizontal directions and -100 to $+100 \mathrm{~mm}$ in the vertical direction. The ranges of 
driving acceleration under full load are -1 to $+1 \mathrm{~g}$ in two orthogonally horizontal directions and -0.8 to $+0.8 \mathrm{~g}$ in the vertical direction.

Five three-component accelerometers with a measuring capacity of up to $6.0 \mathrm{~g}$ were installed at different elevations along the surface of each model slope (Fig. 1). To minimize the boundary effects, sensors were placed along the middle line from the toe to the top of the model. An accelerometer (A0 in Fig. 1) was fixed on the bottom plate of the shaking table to check excitation waves.

\subsection{Input motions}

The horizontal (EW) and vertical (UD) components of the accelerations recorded at the Wolong seismic station during the 2008 Wenchuan earthquake were scaled for the model loading inputs, and the seismograms were released by the China Earthquake Networks Center. The Wolong station is located in Wenchuan County. The altitude on the station ground is $919 \mathrm{~m}$ above sea level and the altitude on the top of the mountain nearby is $3187 \mathrm{~m}$. The overlying soils at the station are mainly composed of Quaternary alluvial, diluvial gravels and pebbles. In the Wenchuan earthquake, the station had the epicentral distance of about $23 \mathrm{~km}$ and recorded the maximum peak ground accelerations, of which the EW- and UD- components were 957.7 gal and 948.1 gal, respectively (Wen et al 2010). The ground motion duration of both components was $108 \mathrm{~s}$, and the corresponding dominant frequencies $\left(f_{d}\right)$ was $2.4 \mathrm{~Hz}$ and $8.1 \mathrm{~Hz}$, respectively. The dominant frequency indicates the maximum response in the Fourier amplitude spectrum. In the test, the EW- and UDrecordings were proportionally scaled into the required horizontal and vertical loading inputs in time domain. All input waves had the duration of $27 \mathrm{~s}$ according to the time scale factor of 4 in Table 1, and the input amplitudes for each kind of loading direction were from 0.1 to $0.8 \mathrm{~g}$ at an interval of $0.1 \mathrm{~g}$. As shown in Fig. 1, the model slopes were excited from the bottom, respectively, by the above horizontal (Xdirection), vertical (Z-direction) waves and their combinations (XZ-direction). The input waves of horizontal and vertical components collected by the accelerometer A0 fixed on the shaking table are shown in Fig. 3, together with their Fourier amplitude spectrums. The dominant frequencies of horizontal and vertical excitation waves are $9.5 \mathrm{~Hz}$ and $32.3 \mathrm{~Hz}$, coinciding well with the similitude relations in section 2.1 (4 times of the dominant frequency of the EW- and UD- components). That's to say, the input waves produced by the table shaking captured the main properties of real recordings. Moreover, the different dominant frequencies of the two component excitations can cause different responses of slope, which is analyzed in the following sections.

The loading sequence of all input waves is given in Fig. 4. It can be seen that besides the Wenchuan waves, sine waves were loaded as input waves alternately. The sine waves had motion frequencies of $5 \mathrm{~Hz}, 7.5 \mathrm{~Hz}, 10 \mathrm{~Hz}, 12.5$ $\mathrm{Hz}$ and $15 \mathrm{~Hz}$, and both the horizontal and the vertical excitation directions were considered in each frequency of motion, except the resultant excitation of two components. Both Wenchuan waves and sine waves were loaded on the model with increasing intensity. For each level of intensity, the models were excited firstly by vertical component followed by horizontal component and the resultant component. Such loading sequence ensures that enough data to be collected before the models completely failed.

The test started with exciting model slopes by a White Noise wave. White Noise is a type of random wave which has the same energy in all frequencies $(<50 \mathrm{~Hz})$. In the power spectrum, the White Noise is a flat line in all frequencies. With this feature, the wave is always used to excite a system to obtain the dynamic characteristics of the system. In the test, the first loading of White Noise was to obtain the initial dynamic characteristics of the model slopes. Another six White Noise excitations were used to excite model slopes at different stages of the test, as shown in Fig. 4. Seven White Noise excitations are denoted by WN1, 2, .. and 7. Based on responding signals in a model under White Noise excitation, the transfer function of the model is obtained. Transfer function determines how a linear system responses to the input. It is a function of frequency, and the frequencies where peak values occur are regarded as the resonance frequencies of the system. Transfer function can be easily calculated using program Matlab's function tfestimate() in Signal Processing Toolbox.

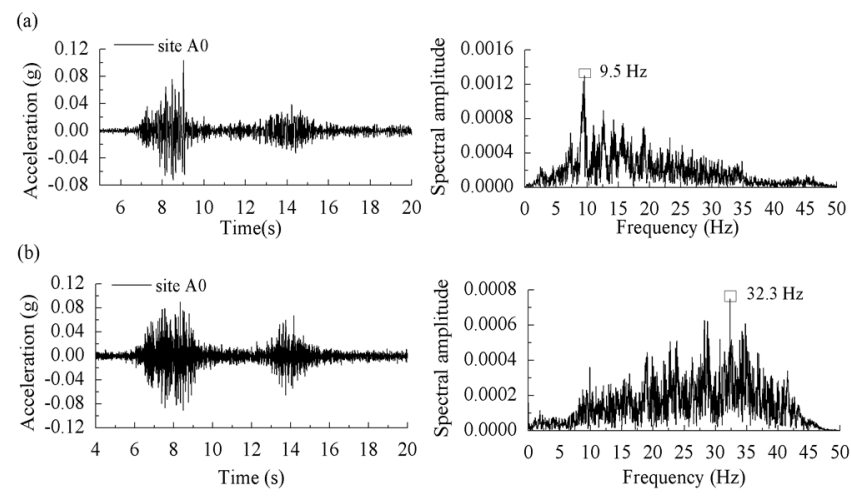

Figure 3. Time history accelerations and their Fourier spectrums for: (a) the horizontal (X-direction) excitation, and (b) the vertical (Zdirection) excitation

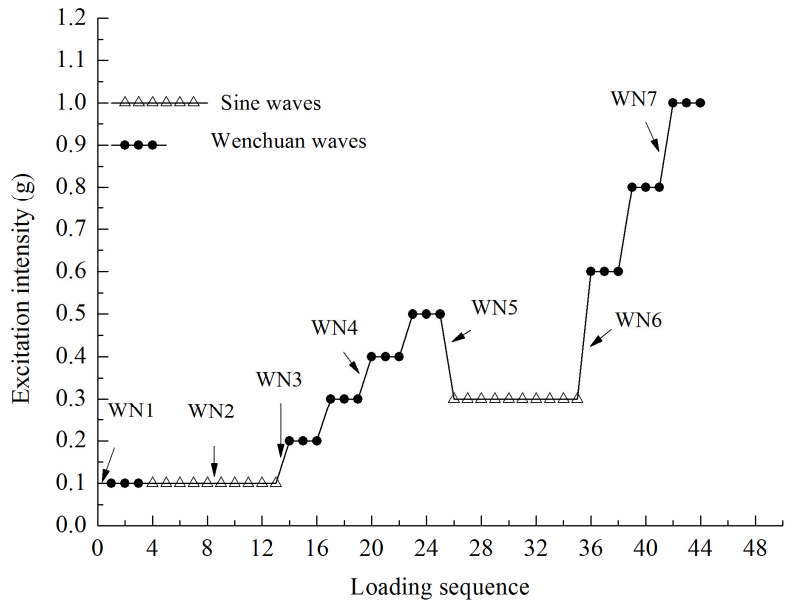

Figure 4. Loading sequence of the shaking table test (the arrows indicate the case where the White Noise wave excites the models) 
(a)

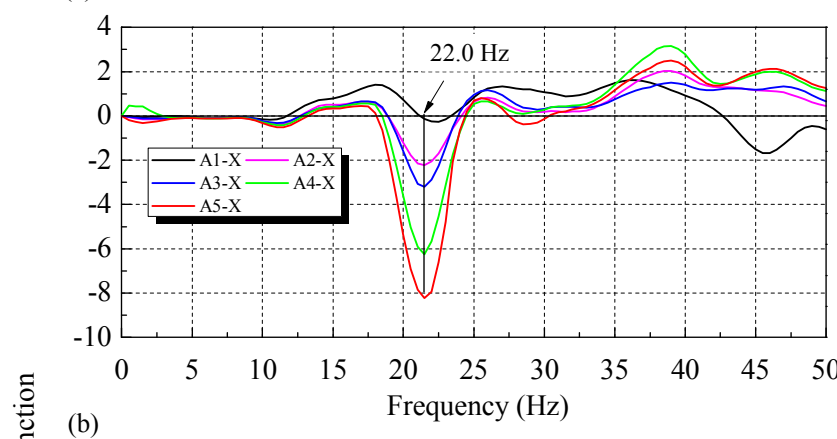

(b)

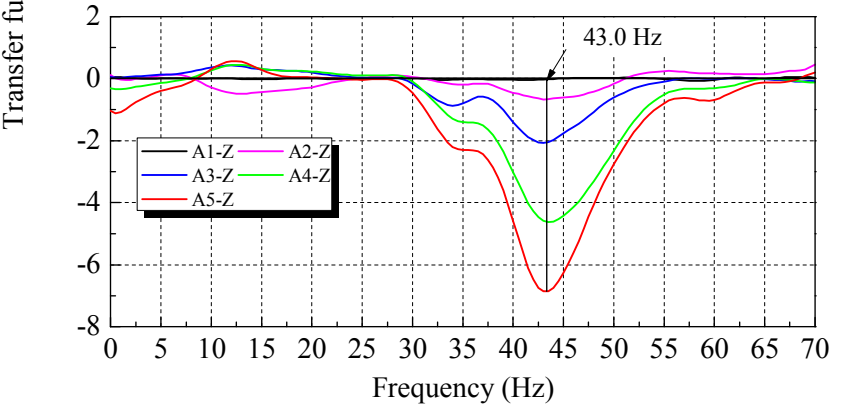

Figure 5. Model slope (HS) transfer functions based on the WN1 excitation for: (a) X-direction shaking, and (b) Z-direction shaking

Table 3. Resonance frequencies, $f_{\mathrm{r}}$, for horizontal $(\mathrm{X})$ and vertical (Z) direction shakings

\begin{tabular}{ccccc}
\hline \multirow{2}{*}{$\begin{array}{l}\text { White } \\
\text { Noise } \\
\text { waves }\end{array}$} & \multicolumn{3}{c}{ Resonance frequency, $\boldsymbol{f}_{\mathbf{r}}(\mathbf{H z})$} \\
\cline { 2 - 5 } & $\mathbf{X}$ & $\mathbf{Z}$ & $\mathbf{X}$ & $\mathbf{Z}$ \\
\hline WN1 & 22 & 43 & 32.5 & 56.5 \\
\hline WN2 & 22 & 43.2 & 32.5 & 56.5 \\
\hline WN3 & 21.8 & 42.8 & 32.4 & 56.5 \\
\hline WN4 & 20.3 & 42.6 & 32.4 & 55.5 \\
\hline WN5 & 18.3 & 42.3 & 31.5 & 54.5 \\
\hline WN6 & 15.6 & 41.4 & 28.5 & 53.2 \\
\hline WN7 & 13.2 & 40.3 & 27.5 & 51.6 \\
\hline
\end{tabular}

Fig. 5 gives the transfer functions calculated at different monitoring points in the HS model, under WN1 excitation. The dominant frequency identified from Fig. 5 is regarded as the resonance frequency $\left(f_{r}\right)$ of the model slope at its initial state. The resonance frequencies for horizontal and vertical shakings are $22.0 \mathrm{~Hz}$ and $43.0 \mathrm{~Hz}$, respectively. In the same way, the initial resonance frequencies of two components for the $\mathrm{HH}$ model are $32.5 \mathrm{~Hz}$ and $56.5 \mathrm{~Hz}$, respectively. Resonance frequencies of two models under seven White Noise excitations are tabulated in Table 3. No resonance would occur, because the dominant frequencies of the input waves during the present tests are totally different from the resonance frequencies of the model slopes. Table 3 also shows that a gradual decreasing tendency of $f_{r}$ simultaneously exists in HS model and $\mathrm{HH}$ model. Furthermore, the maximum drop of $f_{r}$ in $\mathrm{X}$-direction is 8.8
$\mathrm{Hz}$ and $5.0 \mathrm{~Hz}$ for $\mathrm{HS}$ model and $\mathrm{HH}$ model, respectively. The decrease of $f_{r}$ indicates the damage of models which will cause the nonlinear response of the models. The influence of motion frequency will be discussed in the following section.

\section{Results and Discussion}

A column of three-component accelerometers was arranged along the middle line from the toe to the top of each slope surface, i.e. A1, A2, A3, A4 and A5 in the HS model, and A1', A2', A3', A4' and A5' in the HH model. Baseline correction and Butterworth low-pass filtering were conducted using raw dataset to correct it in the Matlab 8.0, before any further analysis. Two dimensionless ratios are used in the following discussion to study the seismic responses of the model slopes in time domain and frequency domain.

\section{Amplification factor}

The amplification factor $\left(R_{\mathrm{PGA}}\right)$ is defined here by the ratio of the peak ground acceleration ( $P G A)$ measured in any monitoring point to that measured on the bottom plate of the table. Such a definition makes $R_{\mathrm{PGA}}>1.0$ indicating real amplification, $R_{\mathrm{PGA}}=1.0$ non-amplification, and $R_{\mathrm{PGA}}<1.0$ attenuation. The considered motion directions in each monitoring point are horizontal (X) and vertical (Z) and their resultant (XZ) as shown in Fig. 1. It is found that even being excited in single direction, the model slope would respond slightly in the other two orthotropic directions. Only responses in the original excitation directions are analyzed to keep the ratio $\left(R_{\mathrm{PGA}}\right)$ being calculated from two accelerations in the same direction. $P G A$ is obtained by taking the maximum absolute value of the measured acceleration in time domain for each monitoring point. The relative elevation $(h / \mathrm{H})$ is defined as the ratio of height $(h$, measured from the toe of the model slope) of any monitoring point to the total height $(\mathrm{H})$ of the slope. So that, the topographic effect is described by $R_{\mathrm{PGA}}$ versus $h / \mathrm{H}$. It should be noted that, the subscript of $R_{\mathrm{PGA}}$ can be replaced by others for different purposes. For instance, $R_{P H A}$ is the ratio of the peak horizontal acceleration ( $P H A)$ measured in any monitoring point to that measured on the bottom plate of the table.

\section{Fourier spectral ratio}

Fourier spectral ratios of accelerations are widely used to obtain frequency characteristics dominating the seismic responses (Murphy et al 1971, Bouchon, 1973, Pedersen et al 1994, Fiore 2010). A dimensionless frequency, $D f / V=D / \lambda$, is additionally calculated to present the relation between frequency content $(f)$ of incident wave and dimension $(D)$ of topography. The dimension $D$ is the vertical height $H$ for a slope, and base width $L$ for a ridge and a canyon. The parameter $V$ is the wave velocity, and $\lambda$ is the wavelength of incident wave with a conversion relation, $\lambda=V / f$. For instance, Ashford et al (1997) observed the peak horizontal amplification at the crest of a slope at $\mathrm{H} / \lambda=0.2$, and Geli et al (1988) obtained a statistic range of $L / \lambda=0.5-2.0$ corresponding to the maximum crest/base ratios for horizontal component motions. 
According to researches by Beresnev et al (1995) and Lee et al (2006), Fourier spectral ratio can also be utilized to estimate the site resonance frequency, especially the fundamental one. Referencing Borcherdt (1970), who took recordings of nearby bedrock as the reference, for a soil site, and Lee et al (2006), who took the readings of downhole bottom as the reference, the bottom plate of the table is used in the present study as the reference site to gain the spectral ratio. The ratio is, therefore, calculated as the record in the model slope divided by that on the table bottom plate. Procedures for this are as follows: (1) Prepare the Fourier amplitude spectrum of corrected accelerogram; (2) Smooth the spectrum using moving average in Matlab 8.0 program; and (3) Calculate the spectral ratio.

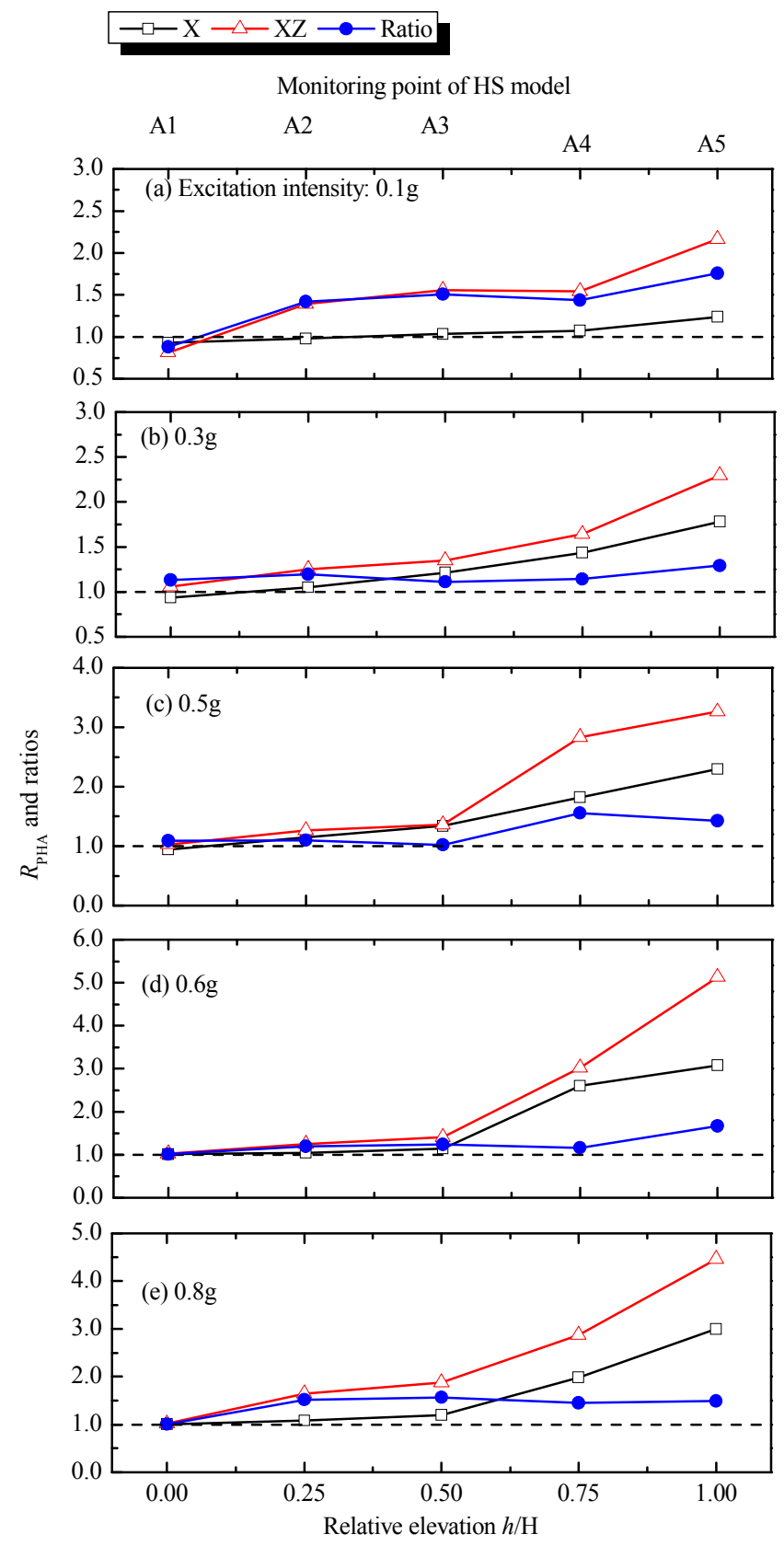

Figure 6. $P H A$ amplification factor, $R_{\mathrm{PHA}}$, by $\mathrm{X}$ - and $\mathrm{XZ}$ - direction shaking and their ratios versus relative elevation $h / \mathrm{H}$ of HS mode

\subsection{Effect of topography}

Figs. 6 and 7 respectively give the amplification factors of peak horizontal accelerations $\left(R_{P H A}\right)$ at different elevations on slope surface of the HS and HH models, subjected to Xand XZ-direction shakings. In general, along the slope elevation, the $R_{P H A}$ tendency in the two kinds of shakings is the same, and it is increasing with increasing relative elevation $h / \mathrm{H}$. The maximum $R_{P H A}$ occurs at the top of the model slopes. Another observation is $R_{P H A}$ demonstrates different change patterns between the upper and lower halves of the model slope. In the upper half $(h / \mathrm{H}>0.5), R_{P H A}$ exceeds 1.5 and increases fast to its maximum at the slope top, indicating an obvious topographic amplification effect.
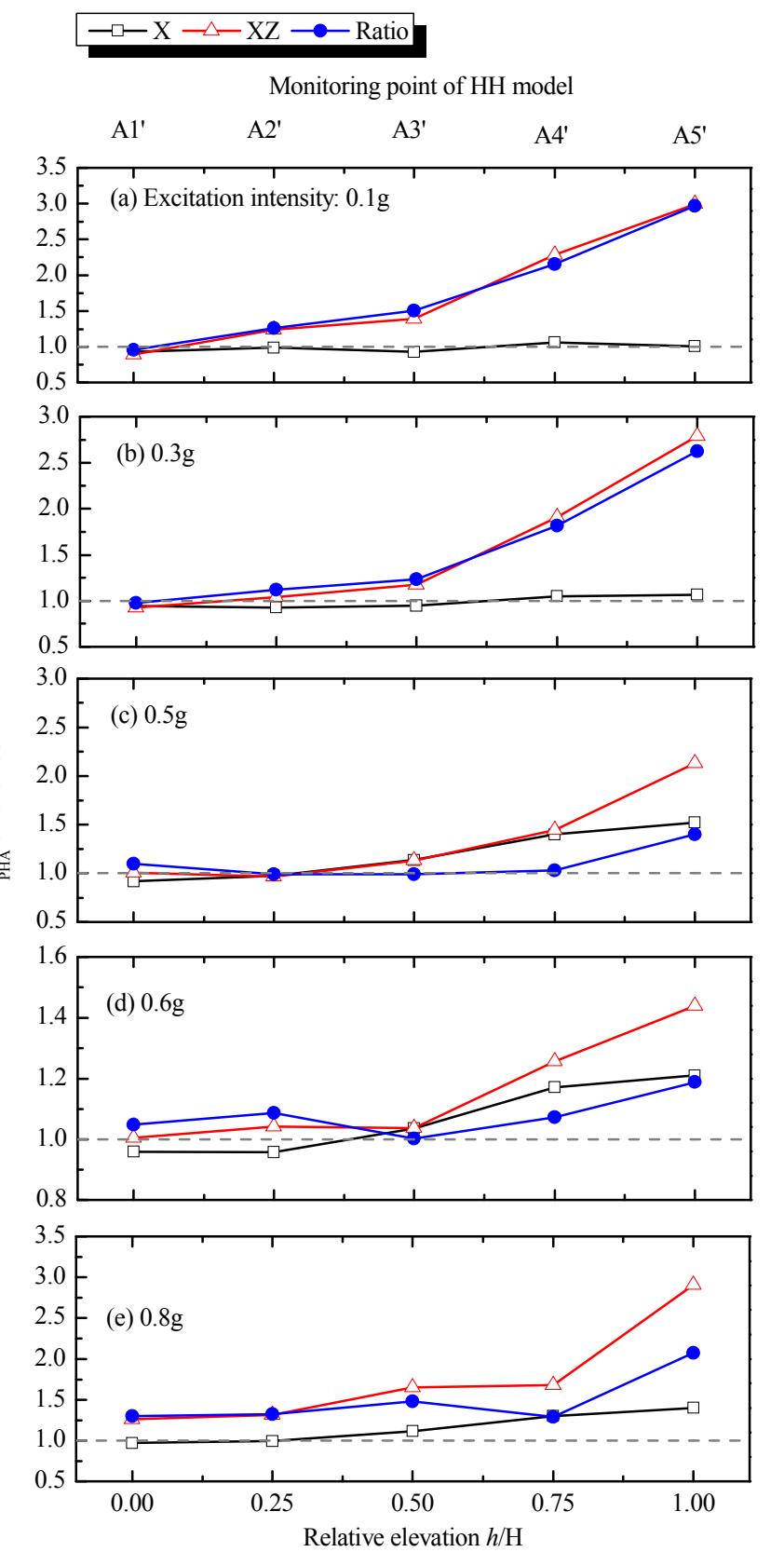

Figure 7. $P H A$ amplification factor, $R_{\mathrm{PHA}}$, by $\mathrm{X}$ - and $\mathrm{XZ}$ - direction shaking and their ratios versus relative elevation $h / \mathrm{H}$ of $\mathrm{HH}$ model 
In the lower half $(h / \mathrm{H} \leq 0.5)$, its dependency on relative elevation is not as strong as that in the upper part. Most of $R_{P H A}$ ranges between 1.0 and 1.5 for the HS model. $R_{P H A}$ is below 1.0 at relative elevations $h / \mathrm{H}=0.0-0.25$ for the $\mathrm{HH}$ model, indicating attenuated horizontal responses at the slope bottom. It means that topographic amplification obtained through crest/base ratios may be overestimated or underestimated without considering the base responses in most researches (Geli et al 1988, Pedersen et al 1994). The reason why the topographic amplification is more obvious in the upper slope part can be explained by the wave reflection on the slope surface.

XZ-direction shaking seems to produce horizontal responses stronger than X-direction shaking, but has no influence on the overall changing tendency of $R_{P H A}$ with elevation. The results of $R_{P H A}$ indicate a maximum increase of $50 \%$ in the lower half of the model, and up to $200 \%$ in the upper half. The difference implies vertical component shakings cause a non-ignorable effect on the final response of horizontal accelerations, especially in the upper slope part. One of the commonly observed phenomena involving strong vertical ground motion is the parabola ejection of the top slope. Yin et al (2009) regarded the ejection as kinetic process for majorities of landslides triggered by the 2008 Wenchuan earthquake, as there is no obvious evidence of friction at the interface. Tang et al (2009) conducted numerical modeling on a simple slope and found that the abrupt ejection was caused by tension waves reflected from upward compression waves ( $\mathrm{P}$ wave). When a slope is filled with structure planes, reflection can occur at any interface, which causes a more complicated effect of vertical earthquake. Aoi et al (2008) presented a trampoline model and explained the asymmetric surface acceleration observed in the 2008 Iwate-Miyagi earthquake in Japan. In their opinion, the upper slope part can be directly uplifted by the strong vertical force and the upward force may speed up failure process by reducing the shear resistance of the slope.

\subsection{Effect of motion direction}

A dimensionless ratio $\left(R_{\mathrm{S}-\mathrm{H}}\right)$ is calculated through dividing PHA of the model with soft rocks (HS model) by that of the model with hard rocks (HH model) for two monitoring points at the same elevation, e.g. $P H A(A 1) / P H A\left(A 1^{\prime}\right)$.

In Fig. 8a, for X-direction shakings, $R_{\mathrm{S}-\mathrm{H}}>1.0$ indicates the HS model produces a larger PHA response than the HH model. The $R_{\mathrm{S}-\mathrm{H}}$ increases along elevation, and the tendency is a little bit faster in the upper half $(h / \mathrm{H}>0.5)$, where $R_{\mathrm{S}-\mathrm{H}}$ also increases as the excitation intensity gets strengthened. For XZ-direction shakings, Fig. $8 \mathrm{~b}$ shows a general increase of $R_{\mathrm{S}-\mathrm{H}}$ along slope elevation in cases where the excitation intensity is larger than $0.4 \mathrm{~g}$. An attenuated $R_{\mathrm{S}-\mathrm{H}}$ below 1.0 is observed in the upper slope part when the excitation intensity is less than $0.4 \mathrm{~g}$. The difference between two kinds of shakings is partly caused by the coupling effect of vertical $(Z)$ component in XZ- direction shakings.

Fig. 8 also shows most of $R_{\text {S-H }}$ values range between 1.0 and 2.0 along the slope elevation, especially at relative elevation $h / \mathrm{H}=0.25-0.75$. A maximum PHA increase of $\mathrm{HS}$ model relative to $\mathrm{HH}$ model occurs at the top slope with
$R_{\mathrm{S}-\mathrm{H}}=2.54$ and 3.56 for $\mathrm{X}$ - and XZ-direction shakings, respectively, when the excitation intensity equals to $0.6 \mathrm{~g}$. At the slope toe and the top, some of $R_{\mathrm{S}-\mathrm{H}}$ are lower than 1.0, and the slope composed of hard rocks (HH model) produces stronger $P H A$ response than that of soft rocks (HS model) by $49 \%$ and $23 \%$, respectively. Besides the coupling effect of Z-component, the irregular topography in the two positions, concave and convex, contributes to the observed phenomena.

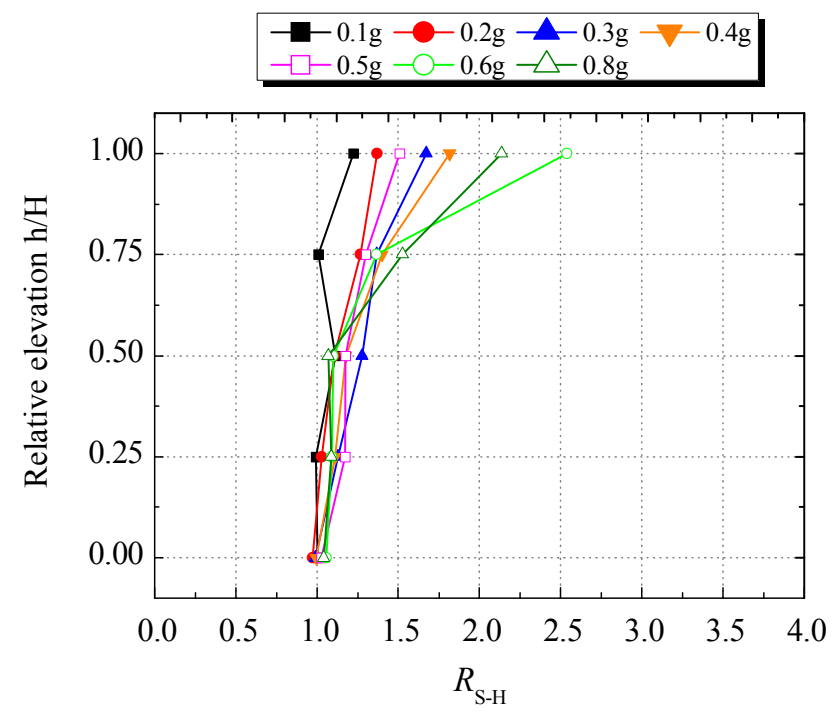

(a) X-direction excitation

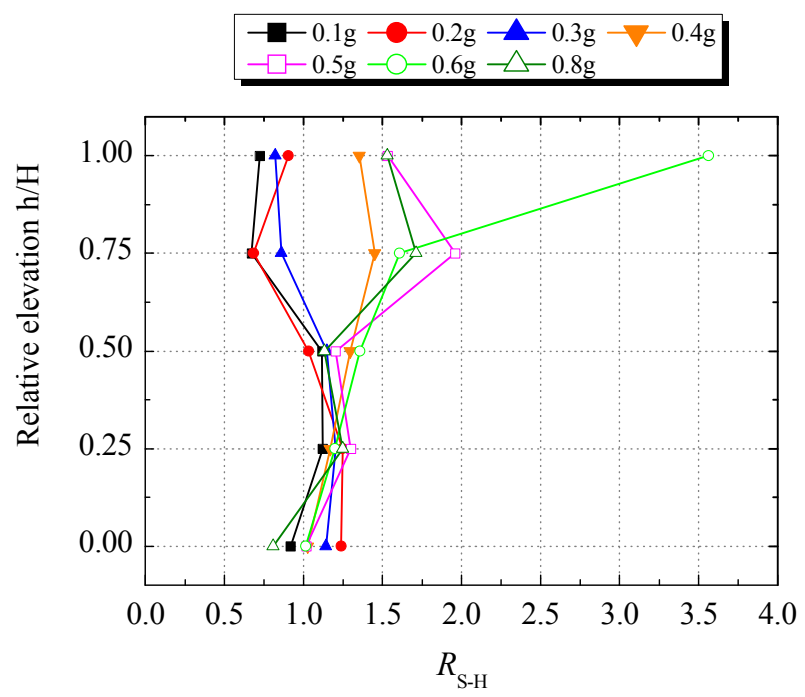

(b) XZ-direction excitation

Figure 8. PHA ratios between two model slopes, $R_{\mathrm{s}-\mathrm{H}}=P H A(\mathrm{HS}$ model)/PHA(HH model), versus relative elevation $h / \mathrm{H}$ for: (a) $\mathrm{X}$ direction shakings, and (b) XZ-direction shakings

\subsection{Effect of motion intensity}

The change of horizontal response with excitation intensity for X- and XZ-direction shakings measured with $P H A$ and $R_{P H A}$ is shown in Fig. 9 for HS model, Fig. 10 for HH model.

It is found that overall the PHAs in all monitoring points on slope surface increase as the excitation intensity gets 

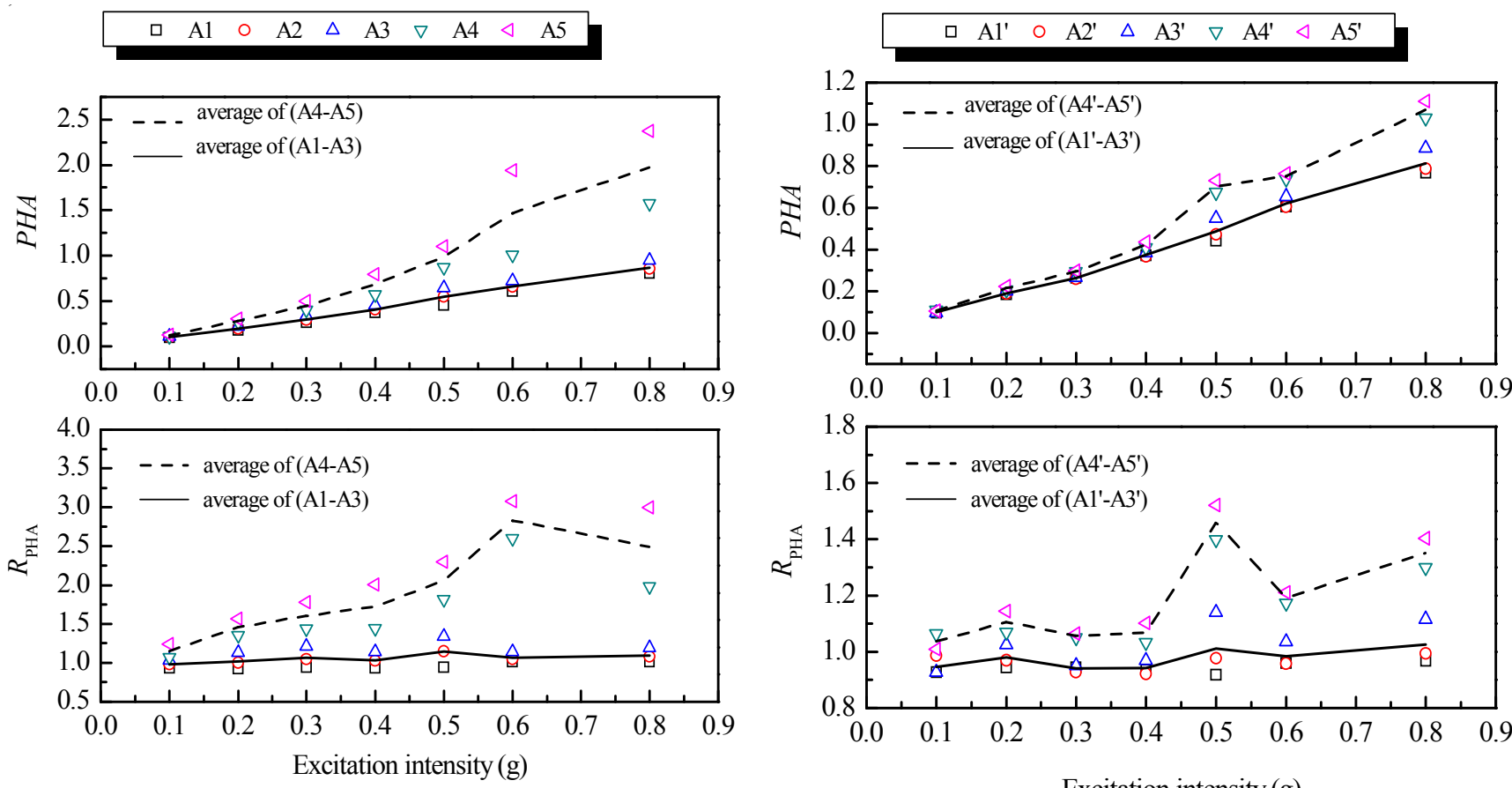

(a) X-direction shakings

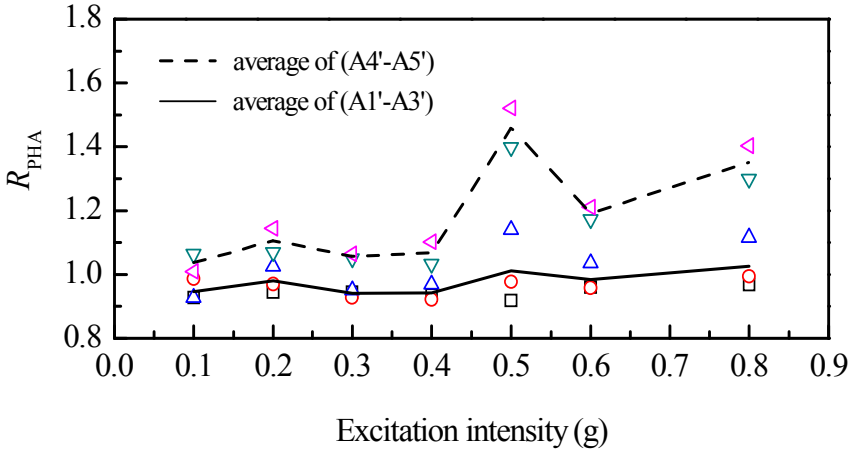

(a) X-direction shakings
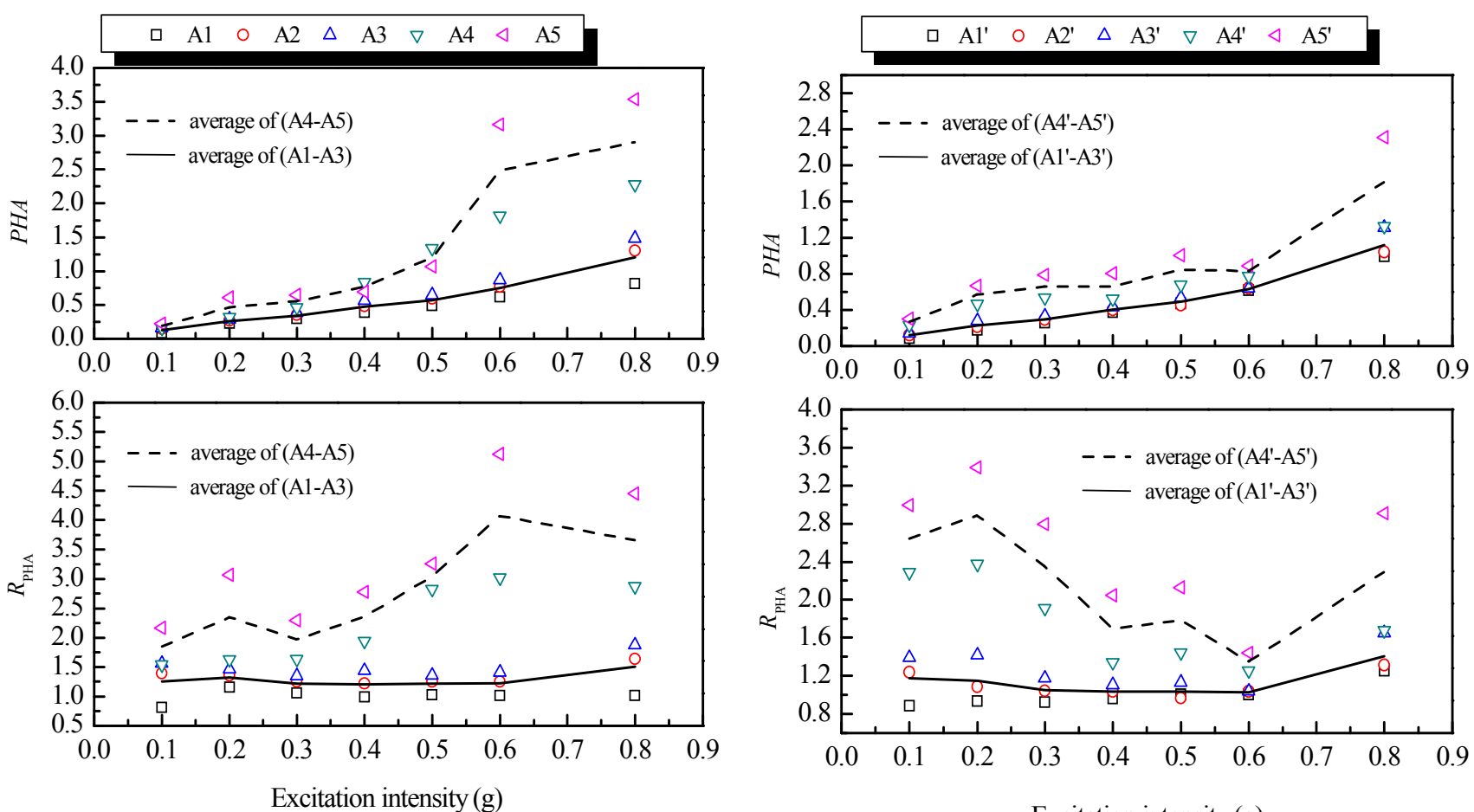

(b) XZ-direction shakings

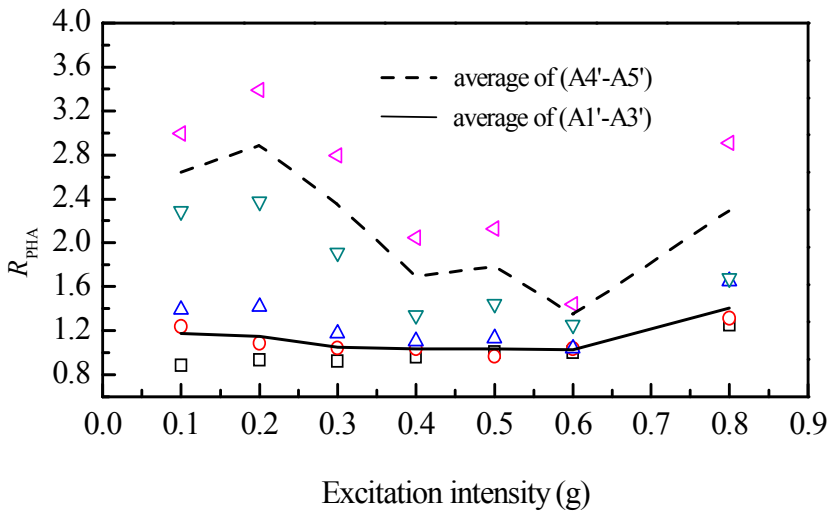

(b) XZ-direction shakings

Figure 9. PHA of HS model and the corresponding $R_{\mathrm{PHA}}$ versus excitation intensity for: (a) X-direction shakings, and (b) XZdirection shakings. The responses of all monitoring points in the lower half of each model $(\mathrm{h} / \mathrm{H} \leqslant 0.5)$ are represented by open symbols. An average of them is calculated and plotted as the dashed line. The responses in the upper half $(\mathrm{h} / \mathrm{H}>0.5)$ are represented by solid symbols, and the average is plotted as solid line.

Figure 10. PHA of $\mathrm{HH}$ model and the corresponding $R_{\mathrm{PHA}}$ versus excitation intensity for: (a) X-direction shakings, (b) XZ-direction shakings. The responses of all monitoring points in the lower half of each model $(\mathrm{h} / \mathrm{H} \leqslant 0.5)$ are represented by open symbols. An average of them is calculated and plotted as the dashed line. The responses in the upper half $(\mathrm{h} / \mathrm{H}>0.5)$ are represented by solid symbols, and the average is plotted as solid line. 
strengthened. However, the corresponding amplification factor, $R_{P H A}$, demonstrates different change tendencies with excitation intensity in the lower and upper slope parts. In the lower half of the two models, a stable oscillation of $R_{P H A}$ between 0.8 and 1.6 is observed, indicating no increase or a minor increase of $R_{P H A}$ with excitation intensity.

For monitoring points in the upper half, $R_{P H A}$ demonstrates strong dependency on excitation intensity. In HS model, the averaged line of A4 and A5 presents a general increase of $R_{P H A}$ with excitation intensity. The increase implies a strengthened topographic amplification effect compared to the stable change of $R_{P H A}$ in the lower half. Three stages of increase are divided corresponding to the excitation intensity from $0.1 \mathrm{~g}$ to $0.4 \mathrm{~g}$ (stage I), $0.4 \mathrm{~g}$ to $0.6 \mathrm{~g}$ (stage II), and $0.6 \mathrm{~g}$ to $0.8 \mathrm{~g}$ (stage III). For stage I, $R_{P H A}$ slowly increases and remains above 1.0. Then a fast increase occurs at stage II, for instance, $R_{P H A}$ at site $\mathrm{A} 5$ increases from 2.8 to 5.1 under XZ-direction shakings. When the excitation intensity continues to increase at stage III, $R_{P H A}$ decreases. The staged change of $R_{P H A}$ can be attributed to the nonlinear property of slope material, which causes significantly different responses when the slope is subjected to strong waves. This kind of nonlinear seismic responses is accompanied by the decrease of resonance frequency $\left(f_{\mathrm{r}}\right)$ of slope and the gradual deterioration of inner structure of slope. As shown in Table 3, the $f_{\mathrm{r}}$ from WN1 to WN4 has a slight decrease, and the slope response can be regarded to be linear, and causes the stable increase of $R_{P H A}$. No visible cracks occur in the model before the 0.6 g-excitation. It should be microscopic disturbance or micro cracking that results in a decreasing trend of $f_{\mathrm{r}}$ (from $20.3 \mathrm{~Hz}$ to $15.6 \mathrm{~Hz}$ ) at stage II. Chen et al (1998) conducted a numerical modeling on damage evolution of rock slope and confirmed that local micro-cracks would not influence the system's linear response. Fig. 11 shows the macro-cracks occurring at the top surface of HS model after the $0.6 \mathrm{~g}$-excitation, which just corresponds to the abrupt increase of $R_{P H A}$ of HS model. Because $f_{\mathrm{r}}$ is decreasing towards the dominant frequency $\left(f_{\mathrm{d}}\right)$ of X-component input motions $(9.6 \mathrm{~Hz})$, the increased probability of resonance makes the PHA response strengthened.

The above explanation applies to the observed increase

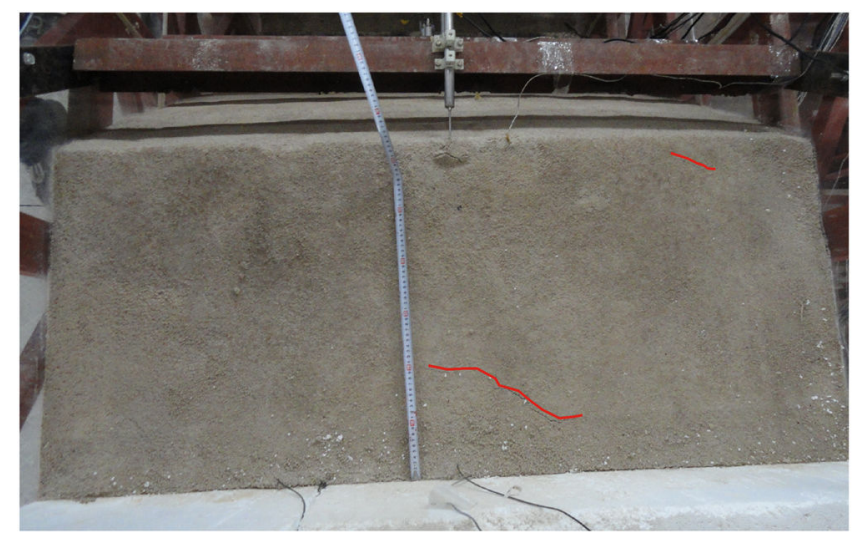

Figure 11. Crack development in HS model indicating the change of slope structure of $R_{P H A}$ in the upper half of $\mathrm{HH}$ model with excitation intensity of X-component shakings. No visible deformation of the model and the large gap between $f_{r}(27.5 \mathrm{~Hz})$ and $f_{d}$ $(9.6 \mathrm{~Hz})$ provide an explanation for the absent final decrease when excitation intensity is increased to $0.8 \mathrm{~g}$. For XZdirection shakings, $R_{P H A}$ demonstrates a gradual decrease with excitation intensity. The possible explanation is the incident X-component motion is offset by the converted motions from the incident $\mathrm{Z}$-component motion upon slope surface.

\subsection{Effect of motion frequency}

Fourier spectral ratios calculated from record in the model relative to that on the bottom table plate are presented as a function of frequency $(f)$ in Figs. 12 and 13 for excitation intensity of $0.1 \mathrm{~g}$ and $0.6 \mathrm{~g}$, respectively. The frequency range is $0 \sim 40 \mathrm{~Hz}(1 \sim 10 \mathrm{~Hz}$ according to a frequency scale factor of 0.25), and includes the typical frequency content of engineering interest. For the case where the excitation intensity is $0.1 \mathrm{~g}$, the results are also presented as a function of dimensionless frequency of $\mathrm{H} / 2 \mathrm{~s}$, i.e., the ratio of the slope height and the wavelength of the input waves. The $\lambda s$ is obtained from $V s / f$, where $V s$ is the shear velocity of model materials and determined by density $\rho$, elasticity modulus $E$ and Poisson's ratio $\mu$ through. Based on values listed in Table 2, the resultant $V_{S}$ is $137 \mathrm{~m} / \mathrm{s}$ for HS model, and $290 \mathrm{~m} / \mathrm{s}$ for HH model.

Fig. 12a shows marked spectral amplification (SA) of site A1 in frequency ranges of $16-23 \mathrm{~Hz}$ and $18-23 \mathrm{~Hz}$ for $\mathrm{X}-$ and XZ-direction shakings, respectively. The SA occurs in higher frequency for $\mathrm{HH}$ model, with the corresponding frequency range of $31-36 \mathrm{~Hz}$ and $31-37 \mathrm{~Hz}$ at site A1'. As relative elevation is increased, the range is elongated to cover larger values. More spectral amplification is also observed in the upper slope part, which accords with the crest amplification of PHA in time domain. In general, the XZdirection shakings produce larger amplification at high frequency than the X-direction shakings, while their SA ratios are close at low frequency and both decrease towards 1.0 as frequency is reduced. Besides amplification, spectral ratio below 1.0 occurs at the slope bottom of HS model subjected to XZ-direction shaking, with a minimum value at frequency of $13 \mathrm{~Hz}$, indicating a frequency-dependent attenuation of $\mathrm{X}$-component response. The same phenomena occurs at the bottom of $\mathrm{HH}$ model and extends to relative elevation $h / \mathrm{H}=0.5$, and the central frequency of attenuation curve is $27 \mathrm{~Hz}$.

Fig. 12 also shows the first peak spectral amplification occurs at $\mathrm{H} / \lambda \mathrm{s}=0.25 \sim 0.3$ for $\mathrm{HS}$ model, and $0.2 \sim 0.25$ for $\mathrm{HH}$ model. A second and third peak also occur at about $\mathrm{H} / \lambda \mathrm{s}=$ 0.4 and 0.5 in HS model. It can be seen that, input waves with wavelength comparable to the slope height produce large amplification, though the material property of slopes and even the dimension of topography are different.

As can be seen from comparison of Figs. 12 and 13, the first peak spectral amplification shifts to lower frequency for both models when the excitation intensity is increased to 0.6 $\mathrm{g}$. It is the same with the decrease of resonance frequency as excitation intensity gets strengthened, and is substantially 
caused by the decay of slope structure. For X-direction shakings, Fig. 13 shows large attenuation with spectral ratio below 1.0 occurs in a broad frequency range of $15-33 \mathrm{~Hz}$ for site A1 and at frequency higher than $27 \mathrm{~Hz}$ for site A1'. As the relative elevation is increased, the spectral ratio in attenuation region gradually decreases, and the corresponding frequency is also narrowed up to disappear. Meanwhile, for XZ-direction shakings, a prominent spectral amplification occurs at high frequency of about $33 \mathrm{~Hz}$ for all monitoring points of HS model, along with several attenuation troughs at frequencies of $20 \mathrm{~Hz}, 30 \mathrm{~Hz}$ and $35 \mathrm{~Hz}$. The observed phenomena, several peaks and troughs at certain frequencies, are attributed to the strong wave reflections and refractions upon micro and macro cracks of slope for high intensity excitation. The result also indicates that the HS model demonstrates a more complex frequencydependent response than the $\mathrm{HH}$ model, due to its vulnerable property to seismic waves.
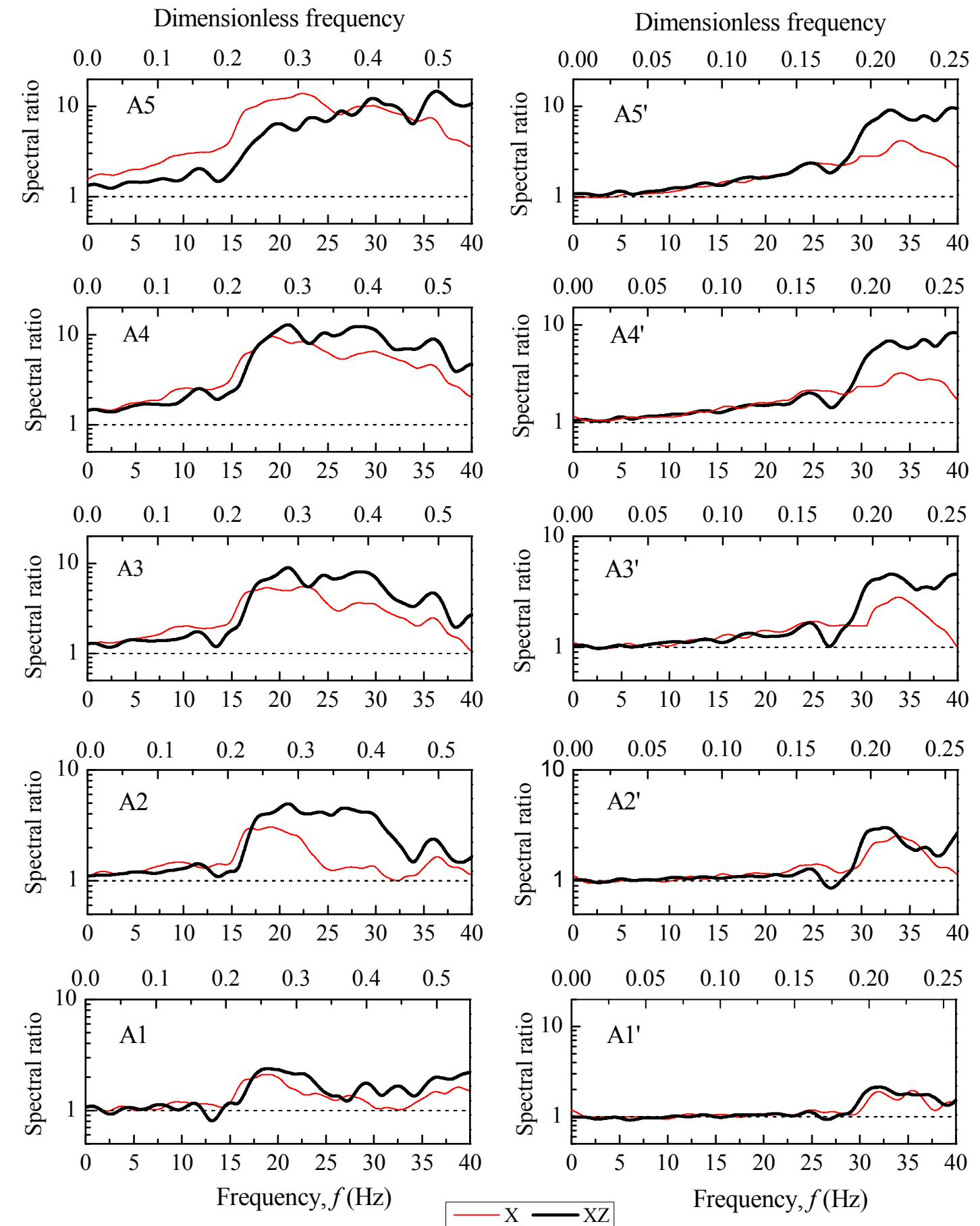

(a) HS model, $V \mathrm{~s}=137 \mathrm{~m} / \mathrm{s}$

(b) $\mathrm{HH}$ model, $V \mathrm{~s}=290 \mathrm{~m} / \mathrm{s}$

Figure 12. Fourier spectral ratios, normalized by motions of the shaking table, at all monitoring points as the excitation intensity is $0.1 \mathrm{~g}$ 

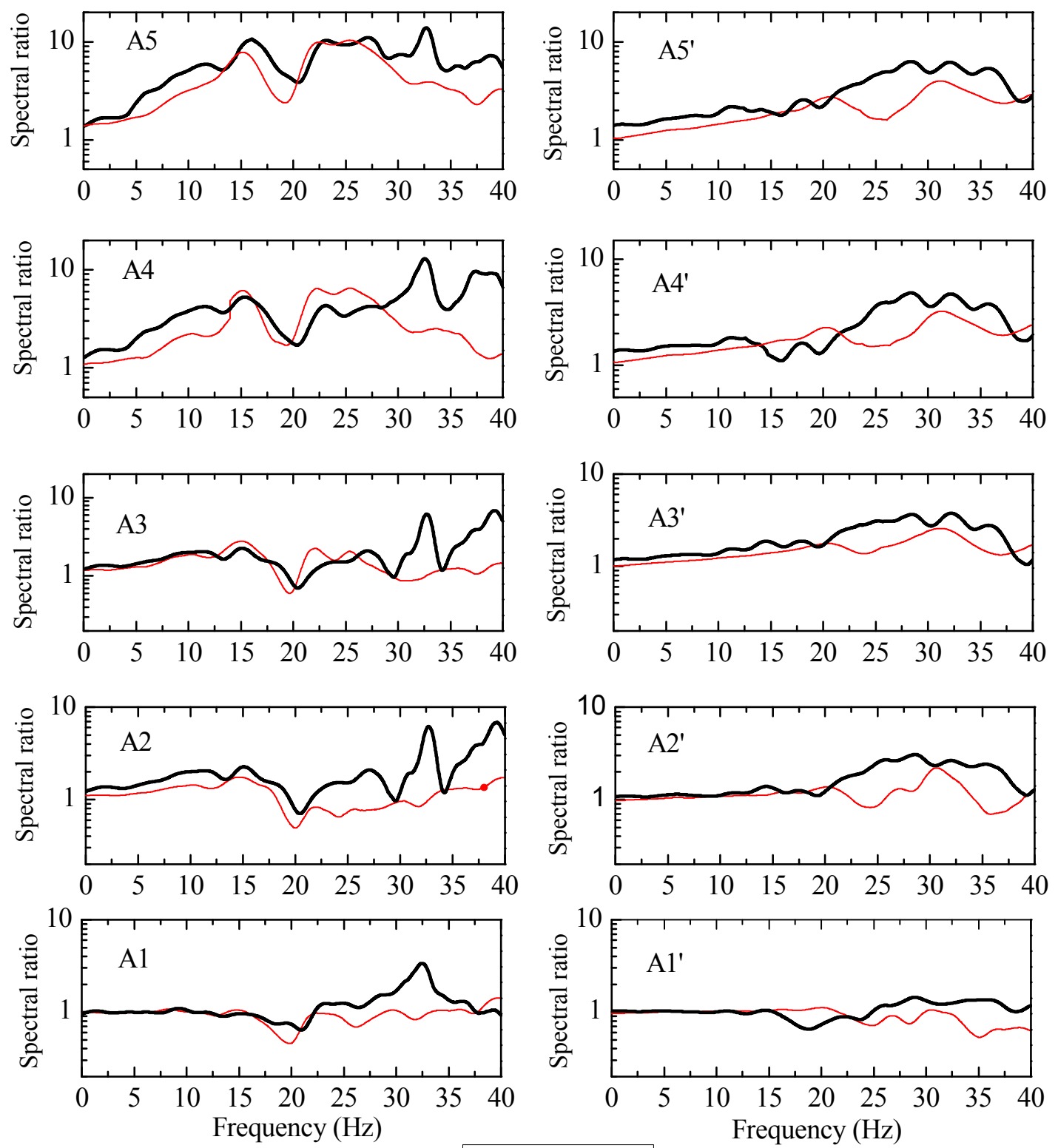

(a) HS model

(b) HH model

Figure 13. Fourier spectral ratios, normalized by motions of the shaking table, at all monitoring points as the excitation intensity is $0.6 \mathrm{~g}$

\section{Conclusions}

An experimental study was conducted on the seismic responses of rock slopes by means of a shaking table. The recorded Wenchuan earthquake waves were scaled to excite the model slopes. Horizontal component acceleration responses were analyzed using parameters of topography, lithology, excitation direction, intensity and frequency. The following conclusions are drawn.

(1) The amplification factor of peak horizontal acceleration $\left(R_{P H A}\right)$ increases with increasing relative elevation $h / \mathrm{H}$ of each model slope. The upper and lower halves of model slopes exhibit different change patterns of $R_{P H A}$. $R_{P H A}$ exceeds 1.5 and increases fast in the upper half $(h / \mathrm{H}>0.5)$, whereas it ranges between 1.0 and 1.5 , even below 1.0 in the lower half $(h / \mathrm{H} \leq 0.5)$, indicating an obvious topographic amplification effect.

(2) Slope composed of low strength materials produces stronger PHA response than that composed of high strength materials with a ratio of 1.0 2.0 at relative elevation $h / \mathrm{H}=$ $0.25-0.75$. The maximum difference occurs at the crest with a ratio larger than 2.5 .

(3) PHA on the surface of each model slope increases with the excitation intensity. The corresponding amplification factor, $R_{P H A}$, keeps stable in the lower slope part, while $R_{P H A}$ shows a general increase in the upper part, indicating the topographic effect on PHA gets strengthened with the excitation intensity.

(4) Slope composed of low strength materials demonstrates spectral amplification at lower frequency than 
that composed of low strength materials. Amplification of two slopes occurs at the similar dimensionless frequency, where the wave length of input waves is comparable to the slope height $(\mathrm{H} / \lambda \mathrm{s}=0.2-0.3)$.

(5) XZ-direction shakings produce larger PHA amplification than X-direction shakings, but has no influence on the overall changing tendency of $R_{P H A}$ with elevation. They also produce larger spectral amplification than Xdirection shakings at high frequencies, while only a little difference occurs at low frequencies.

\section{Acknowledgements}

This research is financially supported by the National Basic Research Program "973" Project of the Ministry of Science and Technology of the People's Republic of China (2013CB733200), the National Science Found for Distinguished Young Scholars of China (Grant No. 41225011), the Chang Jiang Scholars Program of China and the open fund on "Research on large-scale landslides triggered by the Wenchuan earthquake" provided by the State Key Laboratory of Geo-environment Protection and Geo-hazard Prevention. Mr. Wei Zou, Long Wang and Long Chen who assisted in the tests are thanked sincerely. The authors are grateful to all reviewers for their valuable comments on the early version of the manuscript.

\section{References}

Aoi, S., T. Kunugi and H. Fujiwara, 2008. Trampoline effect in extreme ground motion. Science, 322: 727 - 730.

Arias, A., 1970. A measure of earthquake intensity. In: Hansen, R.J. (Ed.), Seismic Design for Nuclear Power Plants. MIT Press, Cambridge, MA, pp. 438 483.Ashford, S.A. and N. Sitar, 1997. Analysis of topographic amplification of inclined shear waves in a steep coastal bluff. Bulletin of the Seismological Society of America, 87(3): 692 - 700.

Ashford, S.A., N. Sitar, J. Lysmer and N. Deng, 1997. Topographic effects on the seismic response of steep slopes. Bulletin of the Seismological Society of America, 87(3): 701 - 709.

Assimaki, D., G. Gazetas and E. Kausel, 2005. Effects of local soil conditions on the topographic aggravation of seismic motion: parametric investigation and recorded field evidence from the 1999 Athens Earthquake. Bulletin of the Seimological Society of America, 95(3): 1059 - 1089.

Beresnev, I.A., K.L. Wen and Y.T. Yeh, 1995. Seismological evidence for nonlinear elastic ground behaviour during large earthquakes. Soil Dynamics and Earthquake Engineering, 14(2): 103 - 114.

Borcherdt, R.D., 1970. Effects of local geology on ground motion near San Francisco Bay. Bulletin of the Seismological Society of America, 60(1): 29 - 61.

Bouchon, M., 1973. Effect of topography on surface motion. Bulletin of the Seismological Society of America, 63(2): $615-632$.

Bouckovalas, G.D. and A.G. Papadimitriou, 2005. Numerical evaluation of slope topography effects on seismic ground motion. Soil Dynamics and Earthquake Engineering, 25(7): 547 - 558.

Bozzano, F., L. Lenti, S. Martino, A. Montagna and A. Paciello, 2011. Earthquake triggering of landslides in highly jointed rock masses: reconstruction of the 1783 Scilla rock avalanche (Italy). Geomorphology, 129(3): $294-308$.

Çelebi, M., 1987. Topographical and geological amplifications determined from strong - motion and aftershock records of the 3 March 1985 Chile earthquake. Bulletin of the Seismological Society of America, 77(4): $1147-1167$.

Çelebi, M., 1991. Topographical and geological amplification: case studies and engineering implications. Structural Safety, 10: 199 - 217.

Chen, Z.H., C.A. Tang and Y.F. Fu, 1998. Infinite element simulation of catastrophe induced by evolution of rock microfracturing damage. Chinese Journal of Geotechnical Engineering, 20: 9 - 15. (in Chinese)

Curtis, W.D., J.D. Logan and W.A. Parker, 1982. Dimensional analysis and the pi theorem. Linear Algebra and its Applications, 47: $117-126$.

Dai, F.C., C. Xu, X. Yao, L. Xu, X.B. Tu and Q.M. Gong, 2010. Spatial distribution of landslides triggered by the 2008 Ms 8.0 Wenchuan Earthquake, China. Journal of Asian Earth Sciences, 40(3): 883 - 895.

Del Gaudio, V. and J. Wasowski, 2007. Directivity of slope dynamic response to seismic shaking. Geophysical Research Letters, 34: L12301.

Dong, J.Y., G.X. Yang, F.Q. Wu and S.W. Qi, 2011. The large-scale shaking table test study of dynamic response and failure mode of bedding rock slope under earthquake. Rock and Soil Mechanics, 32: 2977 - 2983. (in Chinese)

Fiore, D.F., 2010. Seismic site amplification induced by topographic irregularity: Results of a numerical analysis on 2D synthetic models. Engineering Geology, 114(3-4): $109-115$.

Geli, L., P.Y. Bard and B. Jullien, 1988. The effect of topography on earthquake ground motion: A review and new results. Bulletin of the Seismological Society of America, 78(1): 42 - 63.

Gorum, T., X.M. Fan, C.J. Westen, R.Q. Huang, Q. Xu, C. Tang and G.W. Wang, 2011. Distribution pattern of earthquake-induced landslides triggered by the 12 May 2008 Wenchuan earthquake. Geomorphology, 133(1-3): $152-167$.

Lee, C.P., Y.B. Tsai and K.L. Wen, 2006. Analysis of nonlinear site responses using the LSST downhole accelerometer array data. Soil Dynamics and Earthquake Engineering, 26(5): 435 - 460.

Liang, Q.G., W.F. Han, R.Y. Ma and W.W. Chen, 2005. Physical simulation study on dynamic failures of layered rock masses under strong ground motion. Rock and Soil Mechanics, 26(8): 1307 - 1311. (in Chinese)

Lin, M.L. and K.L. Wang, 2006. Seismic slope bahavior in a large-scale shaking table model test. Engineering Geology, 86(2-3): 118 - 133.

Ling, H.I., Y. Mohri, D. Leshchinsky, C. Burke, K. Matsushima and A.H. Liu, 2005. Large-scale shaking 
table tests on Modular-Block reinforced soil retaining walls. J. Geotech. Geoenviron., 131(4): 465 - 476.

Louis, B., 1957. The Pi theorem of dimensional analysis. Archive for Rational Mechanics and Analysis, 1(1): 35 45.

Luo, Y.H., V. Del Gaudio, R.Q. Huang, Y.S. Wang and J. Wasowski, 2014. Evidence of hillslope directional amplification from accelerometer recordings at Qiaozhuang (Sichuan - China). Engineering Geology, 183: 193 - 207.

Murphy, J.R., A.H. Davis and N.L. Weaver, 1971. Amplification of seismic body waves by low - velocity surface layers. Bulletin of the Seismological Society of America, 61(1): 109 - 145.

Pedersen, H., B. Brun, D. Hatzfeld, M. Campillo and P.Y. Bard, 1994. Ground-motion amplitude across ridges. Bulletin of the Seismological Society of America, 84(6): $1786-1800$.

Qi, S.W., Q. Xu, H.X. Lan, B. Zhang and J.Y. Liu, 2010. Spatial distribution analysis of landslides triggered by 2008512 Wenchuan Earthquake, China. Engineering Geology, 116: 95 - 108.

Rogers, A.M., L.J. Katz and T.J. Bennett, 1974. Topographic effects on ground motion for incident $\mathrm{P}$ waves $-\mathrm{a}$ model study. Bulletin of the Seismological Society of America, 64(2): 437 - 456.

Shimizu, Y., ö. Aydan and Y. Ichikaw, 1986. A Model Study on Dynamic Failure Modes of Discontinuous Rock Slopes. Proceedings of the International Symposium on Engineering in Complex Rock Formations. International
Society for Rock Mechanics, 7. Beijing China

Tang, C.A., Y.J. Zuo, S.F. Qin, J.Y. Yang, D.G. Wang, L.C. $\mathrm{Li}$, et al, 2009. Spalling and Slinging Pattern of Shallow Slope and Dynamics Explanation in The 2008 Wenchuan Earthquake. Proceedings of the 10th Conference on Rock Mechanics and Engineering, 258 - 262. Beijing China,

Wang, K.L. and M.L. Lin, 2011. Initiation and displacement of landslide induced by earthquake - a study of shaking table model slope test. Engineering Geology, 122(1-2): $106-114$.

Wen, Z.P., J.J. Xie, M.T. Gao, Y.X. and K.T. Chau, 2010. Near-source strong ground motion characteristics of the 2008 Wenchuan Earthquake. Bulletin of the Seismological Society of America, 100(5B): 2425 - 2439.

Wong, H.L., 1982. Effect of surface topography on the diffraction of P, SV and Rayleigh waves. Bulletin of the Seismological Society of America, 72(4): 1167 - 1183.

Xu, Q., X.J. Pei and R.Q. Huang, 2009. Large-scale Landslides Induced by the Wenchuan Earthquake. Science Press, Beijing. (in Chinese)

Yang, J., T. Sato, S. Savidis and X.S. Li, 2002. Horizontal and vertical components of earthquake ground motions at liquefiable sites. Soil Dynamics and Earthquake Engineering, 22(3): 229 - 240.

Ye, B., G.L. Ye, W.M. Ye and F. Zhang, 2013. A pneumatic shaking table and its application to a liquefaction test on saturated sand. Natural Hazards, 66(2): 375 - 388.

Yin, Y.P., F.W. Wang and P. Sun, 2009. Landslide hazards triggered by the 2008 Wenchuan earthquake, Sichuan, China. Landslides, 6: 139 - 151. 